\title{
Association between dietary patterns and biomarkers of inflammation and antioxidant status in British adults: Results from the National Diet and Nutrition Survey rolling programme Years 1-3
}

Inflammation plays a key role in the development and progression of type 2 diabetes ${ }^{(1)}$. Numerous studies have investigated the association between individual nutrients and foods and biomarkers of inflammation relating to type 2 diabetes ${ }^{(2,3)}$. However, few studies have used robust dietary assessment methods to measure dietary exposure and investigate the association between the whole diet and markers of inflammation and antioxidant status in the UK. This study aimed to assess cross-sectional associations between dietary patterns and markers of inflammation and antioxidant status in British adults.

Participants were adult members (age $>18 \mathrm{yrs}$ ) of the National Diet and Nutrition Survey rolling programme Year 1 to Year 3 , a nationally-representative survey of food and nutrient intake of people living in England, Wales, Scotland and Northern Ireland. A total of 439 survey members with complete data on diet and confounders were analysed. Dietary patterns were identified using principal component analysis and analysed against associated biomarkers of inflammation and antioxidant status using regression methods after adjustment for age, sex, socio-economic status as assessed using National Statistics socio-economic five group classification (ns-sec5), alcohol intake, smoking status, and body mass index (BMI).

General characteristics of study population are shown in Table 1. Four dietary patterns were generated. Of these, the first dietary pattern accounted for the largest proportion of the variance in food intake $(5 \%)$. This pattern was characterised by high consumption of fruit, vegetables, and oily fish, and low consumption of white bread and processed meat products. After adjustment for potential confounders, survey members in the highest quintile of this dietary pattern had significantly higher vitamin $\mathrm{C}($ estimated difference $=$ $15.5 \mu \mathrm{mol} / \mathrm{L} ; 95 \%$ CI: 9.5, 21.6; $P$ value $<0.001)$, and lower white blood cells $\left(-0.8 \times 10^{9} / \mathrm{L} ; 95 \% \mathrm{CI}:-1 \cdot 3,-0 \cdot 3 ; P\right.$ value $\left.=0.002\right)$ compared to survey members in the lowest quintile of this dietary pattern.

\begin{tabular}{|c|c|c|c|}
\hline & & Frequency & (Percentage) \\
\hline Sex & Male & 180 & $(41)$ \\
\hline \multirow[t]{5}{*}{ Ns-sec5 } & Higher managerial and professional occupations & 212 & $(48 \cdot 3)$ \\
\hline & Intermediate occupations & 43 & $(9 \cdot 8)$ \\
\hline & Small employers and own account workers & 40 & $(9 \cdot 1)$ \\
\hline & Lower supervisory and technical occupations & 96 & $(21.9)$ \\
\hline & Routine occupations & 48 & $(10 \cdot 9)$ \\
\hline \multirow[t]{4}{*}{ Alcohol (Units/day) } & None & 136 & (31) \\
\hline & $\leq 4$ (men),$\leq 3$ (women) & 109 & $(24 \cdot 8)$ \\
\hline & $>4$ and $\leq 8$ (men), $>3$ and $\leq 6$ (women) & 80 & $(18 \cdot 2)$ \\
\hline & $>8$ (men), $>6$ (women) & 114 & (26) \\
\hline \multirow[t]{4}{*}{ BMI $\left(\mathrm{kg} / \mathrm{m}^{2}\right)$} & 18.5 and below 25 & 154 & $(35 \cdot 1)$ \\
\hline & 25 and below 30 & 157 & $(35 \cdot 8)$ \\
\hline & 30 and below 40 & 114 & (26) \\
\hline & Over 40 & 14 & $(3 \cdot 2)$ \\
\hline \multirow[t]{3}{*}{ Smoking status } & Current cigarette smoker & 99 & $(22 \cdot 6)$ \\
\hline & Ex-regular cigarette smoker & 93 & $(21 \cdot 2)$ \\
\hline & Never regular cigarette smoker & 247 & $(56 \cdot 3)$ \\
\hline
\end{tabular}

In conclusion, a dietary pattern rich in fruit, vegetables and oily fish is associated with improved inflammatory and antioxidant status. Further investigations are required to assess if this dietary pattern is related to lower prevalence of diabetes and improved glycaemic control in British adults.

1. Calle MC and Fernandez ML (2012). Diabetes Metab 38, 183-91.

2. Nettleton JA, Steffen LM, Schulze MB et al. (2007). Am J Clin Nutr 85, 1615-1625.

3. Heidemann C, Hoffmann K, Spranger J et al. (2005). Diabetologia, 48, 1126-1134. 